\section{CIVILTEC}

Revista Técnico-Cientifica

de Engenharia Civil
Volume 2-n. $2-2021$

hitpp://periodicos.unesc.net/engcivil

\title{
Avaliação de misturas solo-cal-pó de vidro com adição de fibras de polipropileno submetidas a ensaios de resistência à compressão simples
}

Doi: http://dx.doi.org/10.18616/civiltec.v2i2.6853

\author{
Aziz Tebechrani Neto ${ }^{1}$ \\ Brenda Rielli Spier Correa ${ }^{2}$ \\ Laís Verissimo do Nascimento ${ }^{3}$ \\ Lucas Eduardo Dornelles ${ }^{4}$
}

\section{Introdução}

Devido à disponibilidade de sílica em estado amorfo, o pó de vidro apresenta atividade pozolânica. Assim, quando finamente moído e na presença de água, a sílica é capaz de reagir com o hidróxido de cálcio da cal e formar compostos cimentantes. Na geotecnia, suas características estudadas por diversos autores (OLUFOWOBI et al., 2014; BENNY et al., 2017; GULLU et al., 2017; CONSOLl et al., 2018) comprovam o seu potencial de aplicação em estabilização de solos finos. A cal de carbureto é um resíduo cimentante gerado na produção do gás acetileno. Alguns autores (SALDANHA et al., 2018; BILONDI et al., 2018; SCHEUERMANN FILHO, 2019) avaliaram a utilização da cal de carbureto em aplicações geotécnicas e obtiveram bons resultados. Com relação às fibras de polipropileno, estas são consideradas as mais promissoras para utilização em estabilização de solos, muito devido à sua alta resistência à tração, inerência à água e flexibilidade de aplicação. Nesse contexto, o presente trabalho propõe a avaliação do desempenho mecânico de um solo residual argiloso com adição de pó de vidro moído, cal de carbureto e fibras de polipropileno.

\footnotetext{
1 Mestre em Engenharia Civil, Universidade Federal do Rio Grande do Sul, Porto Alegre, aziztneto@gmail.com 2 Mestra em Engenharia Civil, Universidade Federal do Rio Grande do Sul, Porto Alegre, brenda.correa94@gmail.com 3 Mestra em Engenharia Civil, Universidade Federal do Rio Grande do Sul, Porto Alegre, laisverissimonascimento@gmail.com 4 Mestre em Engenharia Civil, Universidade Federal do Rio Grande do Sul, Porto Alegre, lucascivilufsm@gmail.com
} 


\section{CIVILTEC}

Revista Técnico-Científica

de Engenharia Civil
Volume $2-$ n. 2 - 2021

http://periodicos.unesc.net/engcivil

\section{Metodologia}

O solo utilizado na presente pesquisa é oriundo da cidade de ljuí-RS, classificado como um solo argiloso. Através de ensaio de difração de raios-X (DRX), foi possível observar fases mineralógicas de caulinita, esmectita e hematita. A tabela 1 - Índices físicos do solo de ljuíRS apresenta as características desse material com as respectivas normativas utilizadas.

Tabela 1. Índices físicos do solo de ljuí-RS. (Fonte: elaboração própria)

\begin{tabular}{lll}
\hline Índices Físicos & Resultado & Normativa utilizada \\
\hline Limite de Liquidez (LL) & 79 & ABNT NBR 6459 \\
Limite de Plasticidade (LP) & 60 & ABNT NBR 7180 \\
Índice de Plasticidade (IP) & 19 & - \\
Peso específico real dos grãos (Gs) & $2,89 \mathrm{~g} / \mathrm{cm}^{3}$ & ABNT NBR 6508 \\
\%Areia média & $10 \%$ & ABNT NBR 6502 \\
\%Areia fina (0,06>d>0,2mm) & $10 \%$ & ABNT NBR 6502 \\
\%Silte (0,002>d>0,06mm) & $37 \%$ & ABNT NBR 6502 \\
\%Argila (d>0,002mm) & $43 \%$ & ABNT NBR 6502 \\
Classificação SUCS & $\mathrm{CH}$ & - \\
Índice de Suporte Califórnia (\%) & 5,2 (Energia normal) & ABNT NBR 9895 \\
Expansão (\%) & 2,21 (Energia normal) & ABNT NBR 9895 \\
\hline
\end{tabular}

Com relação à adição de pó de vidro, optou-se por utilizar apenas vidro de garrafas de coloração verde. Ensaios de difração e fluorescência de raios-X (DRX e FRX) mostraram que esse material apresenta um alto grau de amorfização e um alto teor de sílica $\left(\mathrm{SiO}_{2}\right)$ na sua composição. $O$ vidro foi moído em moinho de bolas e apenas o vidro moído passante na peneira de n. 200 foi utilizado na mistura. A cal de carbureto foi utilizada como aglomerante na mistura. Ensaio FRX determinou que o material é formado predominantemente (74\%) por óxido de cálcio $(\mathrm{CaO})$, responsável pela formação do $\mathrm{Ca}(\mathrm{OH})_{2}$. A fibra de polipropileno, utilizada com o intuito de reforçar o solo, mede $24 \mathrm{~mm}$ de comprimento e 0,023 $\mathrm{mm}$ de diâmetro, com resistência à tração de $120 \mathrm{MPa}$, módulo de elasticidade de $3 \mathrm{GPa}$.

Para a realização dos ensaios de Resistência à Compressão Simples, foram adotadas as seguintes variáveis: peso específico aparente seco $\left(14\right.$ e $\left.15 \mathrm{kN} / \mathrm{m}^{3}\right)$, teor de vidro moído $(10 \%$ e $20 \%$ ), teor de cal de carbureto (3\% e $6 \%$ ) e teor de fibra de polipropileno (0\% e $0,15 \%)$. Para tanto, foram ensaiados 32 corpos de prova, em duplicatas, moldados por um molde metálico tripartido com $5 \pm 0,1 \mathrm{~cm}$ de diâmetro e $10 \pm 0,1 \mathrm{~cm}$ de altura. A umidade ótima, obtida por meio do ensaio de compactação de energia normal, foi fixada em $30 \%$. 


\section{CIVILTEC}

Revista Técnico-Científica

de Engenharia Civil

\section{Volume 2 - n. 2 - 2021}

http://periodicos.unesc.net/engcivil

Na moldagem, os materiais secos (areia, vidro, cal e fibra) foram misturados e, em seguida, adicionou-se a água até a mistura se tornar homogênea. Posteriormente, a mistura foi compactada estaticamente em três camadas iguais no molde metálico.

O processo de cura ocorreu em um período de 28 dias, durante os quais os 32 corpos de prova foram armazenadas em sacos plásticos dentro de uma câmara úmida. Um dia antes de atingir o tempo de cura, os corpos de prova foram submersos em água.

Por fim, a resistência à compressão simples das misturas foi avaliada seguindo as recomendações da norma ASTM C39 (ASTM, 2010) em prensa hidráulica.

\section{Resultados}

As variáveis foram analisadas através de um software estatístico, onde são mostradas as variáveis controladas que tiveram maior efeito na mistura, para as proporções estabelecidas nesta pesquisa.

Como pode ser observado na figura 1: análise estatística relacionada à resistência à compressão simples emb, pelo gráfico de efeitos principais, o teor de cal foi a variável que obteve maior efeito nas misturas, seguido da densidade aparente seca e do teor de fibras e vidro moído. Com o gráfico de Pareto (figura 1: análise estatística relacionada à resistência à compressão simples ema), pode-se perceber que o fator (variável controlada) mais significativo foi o teor de cal, seguido da densidade aparente seca. Nota-se também que as interações de segunda ordem de algumas variáveis também possuem relevância.

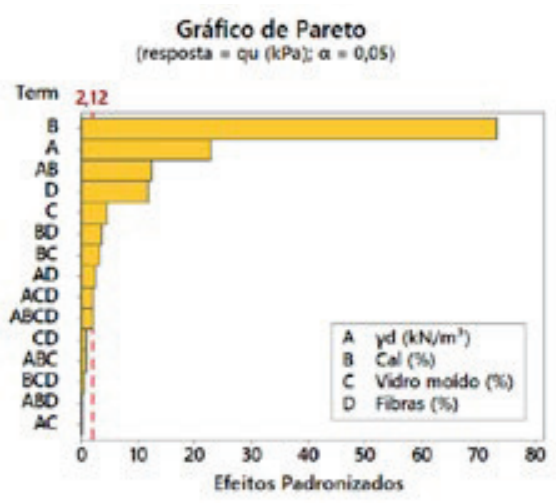

(a)

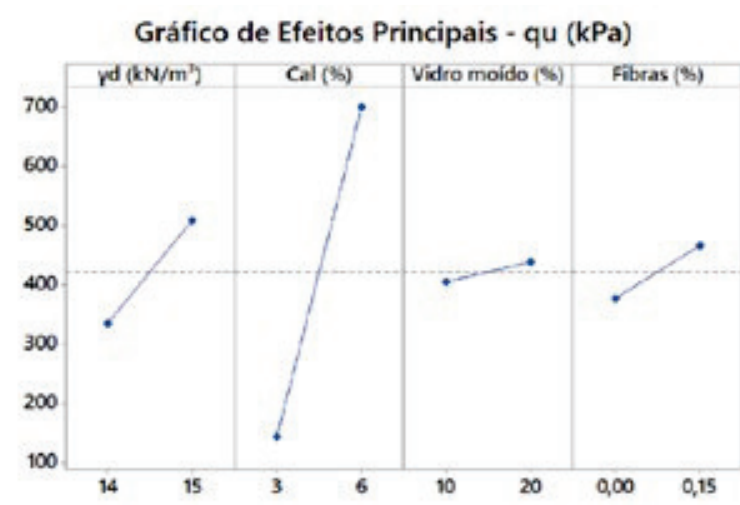

(b)

Figura 1. Análise estatística relacionada à resistência à compressão simples em (a) gráfico de Pareto e (b) gráfico de efeitos principais. (Fonte: elaboração própria) 


\section{CIVILTEC}

Revista Técnico-Científica

de Engenharia Civil
Volume $2-$ n. $2-2021$

http://periodicos.unesc.net/engcivil

Os valores de resistência à compressão simples foram relacionados ao índice de porosidade/teor volumétrico de cal, no mesmo processo feito por Consoli, Lopes Junior, Heineck (2009a) e Consoli et al. (2009b).

Os resultados de resistência à compressão simples (qu) para os espécimes sem presença de fibras estão apresentados na figura 2a, com coeficiente de determinação $\left(R^{2}\right)$ igual a $96 \%$, sendo a equação resultante apresentada na supracitada figura. Da mesma forma, os espécimes com presença de fibras estão representados na figura $2 \mathrm{~b}$ e obtiveram um coeficiente de determinação igual a $98 \%$.

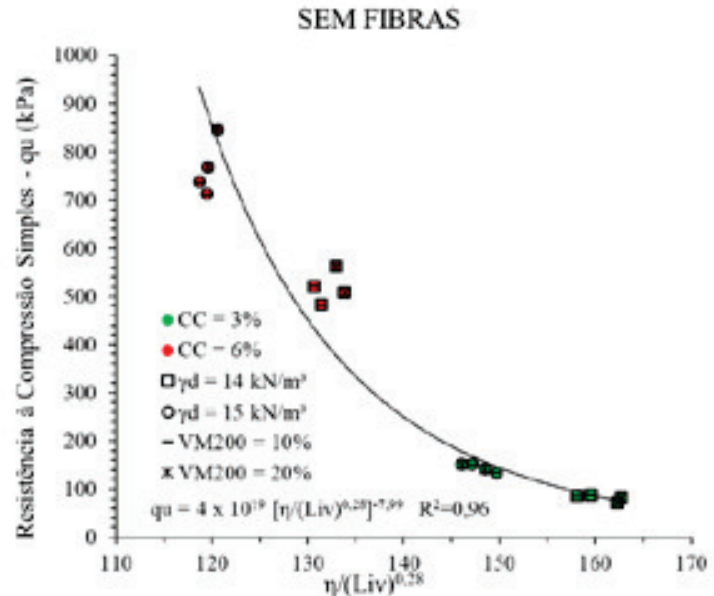

(a)

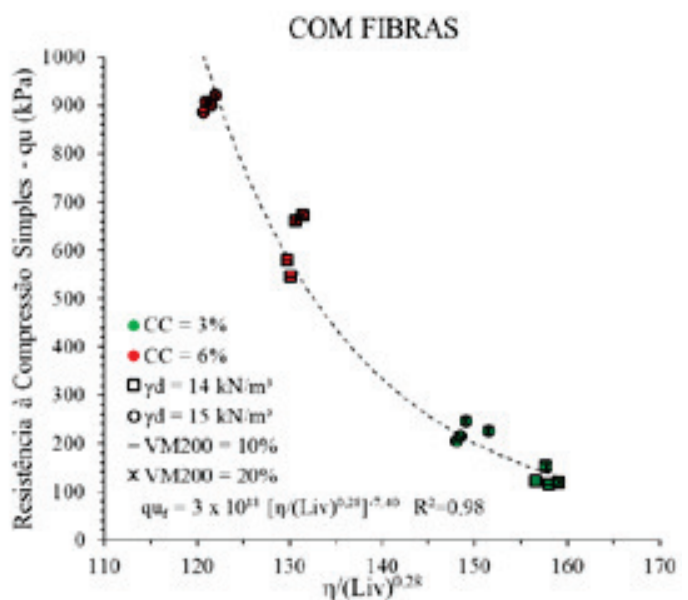

(b)

Figura 2. Relação das variáveis resposta com o índice $\eta /$ Liv: $q_{u}$ (a) sem fibras e (b) com fibras. (Fonte: elaboração própria)

Pode-se observar que a presença das fibras em relação aos valores obtidos referentes à compressão simples resultou num sucinto aumento na resistência, sendo praticamente insignificante a adição de fibras para este ensaio.

\section{Conclusão}

Com base no que foi proposto e avaliado no trabalho, pode-se concluir que a estabilização do solo em estudo com cal de carbureto, vidro moído e fibras apresentou resultados satisfatórios em termos de resistência e da mistura, sendo a cal de carbureto a responsável pelos maiores ganhos de resistência, seguido pelo peso específico aparente seco e, em menores proporções, do teor de fibras e de vidro moído. Referindo-se à relação entre as variáveis respostas com o índice $\eta /$ Liv, a adição de fibras na mistura mostrou-se praticamente irrelevante para o aumento da resistência da mistura. 


\section{CIVILTEC}

Revista Técnico-Científica

de Engenharia Civil
Volume $2-$ n. 2 - 2021

http://periodicos.unesc.net/engcivil

Palavras-chave: Estabilização de Solos. Pó de Vidro. Fibras de Polipropileno. Resistência à Compressão Simples. Rigidez.

Agradecimentos: os autores expressam seus agradecimentos ao Conselho Nacional de Desenvolvimento Científico e Tecnológico (CNPq) pelo fomento à pesquisa.

\section{Referências}

AMERICAN SOCIETY FOR TESTING AND MATERIALS. ASTM C39. Standard test method for compressive strength of cylindrical concrete specimens. West Conshohocken, 2010.

ASSOCIAÇÃO BRASILEIRA DE NORMAS TÉCNICAS. NBR 6459: determinação do limite de liquidez. Rio de Janeiro, 1984.

NBR 7180: determinação do limite de plasticidade. Rio de Janeiro, 1984.

NBR 6502: rochas e solos. Rio de Janeiro, 1995.

NBR 9895: solo - Índice de Suporte Califórnia (ISC). Rio de Janeiro, 2016.

BENNY, J. R.; JOLLY, J.; MAREENA, S. J.; THOMAS, M. Effect of glass poder on engineering properties of clayedy soil. International Journal of Engineering Research \& Technology. 6., 2017.

BILONDI, M. P.; TOUFIGH, M. M.; TOUFIGH, V. Using calcium carbide residue as na alkaline activator for glass powder-clay geopolymer. Construction and Building Materials. 183. p. 417-428, 2018.

CONSOLI, N. C.; LOPES JUNIOR, L. S.; HEINECK, K. S. Key parameters for the strength control of lime stabilized soils. Journal of Materials in Civil Engineering, v. 21(5), p. 210-216, 2009a.

CONSOLI, N. C.; LOPES JUNIOR, L. S.; FOPPA, D.; HEINECK, K. S. Key parameters dictating strength of lime/cement-treated soils. Geotechnical Engineering, v. 162 (GE2), p. 111-118, 2009b.

CONSOLI, N. C.; WINTER, D.; LEON, H. N.; SCHEUERMANN FILHO, H. C. Durability, strength and stiffness of green stabilized sand. Journal of Geotechnical and Geoenvironmental Engineering, v. 144(9), p. 1-10, 2018.

GULLU, H.; CANAKCI, H.; AL ZANGANA, I. F. Use of cement based grout with glass powder for deep mixing. Construction and Building Materials. n. 137, p. 12-20, 2017.

OLUFOWOBI, J.; OGUNDOJU, A.; MICHAEL, B.; ADERINLEWO O. Clay soil stabilisation using powdered glass. Journal of Engineering Science and Technology, n. 9, p. 541-558, 2014.

SALDANHA, R. B., SCHEUERMANN FILHO, H. C., MALLMANN, J. E. C., CONSOLI, N. C., REDDY, K. R. Physical-mineralogical-chemical characterization of carbide lime: An environment-friendly chemical additive for soil stabilization. Journal of Materials in Civil Engineering, v. 30(6), p. 1-7, 2018.

SCHEUERMANN FILHO, H. C. Estabilização de um Solo Dispersivo com Pó de Vidro Moído e Cal de Carbureto. 2019. 205 f. Dissertação (Mestrado em Engenharia Civil) - Universidade Federal do Rio Grande do Sul. Porto Alegre, 2019. 